\title{
A systematic review and meta-analysis of efficacy and safety of negative pressure wound therapy in the treatment of diabetic foot ulcer
}

\author{
Lin Chen ${ }^{1}$, Shuang Zhang ${ }^{1}$, Jun $\mathrm{Da}^{1}$, Wencong Wu${ }^{1}$, Fei Ma ${ }^{1}$, Chao Tang ${ }^{1}$, Guangzhou Li ${ }^{1}$, Dejun Zhong ${ }^{1}$,

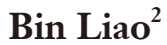

${ }^{1}$ Department of Orthopedics, the Affiliated Hospital of Southwest Medical University, Luzhou, China; ${ }^{2}$ Department of Supply Room, the Affiliated Hospital of Southwest Medical University, Luzhou, China

Contributions: (I) Conception and design: All authors; (II) Administrative support: All authors; (III) Provision of study materials or patients: All authors; (IV) Collection and assembly of data: All authors; (V) Data analysis and interpretation: All authors; (VI) Manuscript writing: All authors; (VII) Final approval of manuscript: All authors.

Correspondence to: Bin Liao. Department of Supply Room, the Affiliated Hospital of Southwest Medical University, 25 Taiping Street, Luzhou 646000, China. Email: liaobin0808789@163.com.

\begin{abstract}
Background Negative pressure wound therapy (NPWT) is one of the new modality for the treatment of diabetic foot ulcers. In this article we will investigate the efficacy and safety of it by literature search and meta-analysis.

Methods: The databases of PubMed, Embase, Ovid, and Cochrane library were selected as search platforms. Randomized controlled trials (RCTs) published after 2010 were searched with the keyword "vacuum-assisted closure therapy" OR "negative pressure wound therapy" OR "diabetic foot". The Cochrane Review Handbook was used to assess the bias of the literatures. The software RevMan 5.4 was used for analysis to obtain a forest plot and funnel plot.
\end{abstract}

Results: In this study, 363 articles were initially screened, and 9 literatures were finally included, involving a total of 943 patients. Combined analysis using the fixed effects model showed that the healing rate of the NPWT group was significantly lower than the standard group [odds ratio $(\mathrm{OR})=3.60,95 \%$ confidence interval (CI): 2.38 to $5.45, \mathrm{P}<0.001]$. The granulation tissue formation time of the NPWT group was significantly less than the standard group [mean difference $(\mathrm{MD})=-8.95,95 \% \mathrm{CI}:-10.26$ to $-7.64, \mathrm{P}<0.001$ ]. The rate of adverse events of both groups showed no significant difference (OR $=0.49,95 \%$ CI: 0.10 to 2.42 , $\mathrm{P}=0.38$ ). The amputation rate of both groups showed no statistically significant (OR $=0.33,95 \% \mathrm{CI}: 0.09$ to $1.26, \mathrm{P}=0.10)$ too.

Discussion: Negative pressure wound therapy can effectively accelerate wound healing, it is equally safe with general routine treatment. However, the negative pressure value should be appropriately maintained and adjusted to avoid bleeding tendency of the wound when applying this new modality.

Keywords: Negative pressure wound therapy; diabetic foot (DF); ulcer; safety; meta-analysis

Submitted Aug 16, 2021. Accepted for publication Sep 24, 2021.

doi: 10.21037/apm-21-2476

View this article at: https://dx.doi.org/10.21037/apm-21-2476

\section{Introduction}

In recent years, with the increase in the incidence of diabetes, complications caused by diabetes have increased (1). Diabetic foot (DF) is a common diabetic complication caused by hyperglycemia, resulting the peripheral nerve and vascular lesions, producing a dry and irritated skin on the foot, and finally leading to the formation of ulcers, which do not heal for a long time 
and lower the quality of life of the patients (2). With the development of new medical treatments, many new modalities have been gradually applied in the treatment of wounds under the guidance of cytohistology and biochemistry (3). Negative pressure wound therapy (NPWT) is one such modality, which can be used for the treatment of superficial wounds and the drainage of deep wounds, and can completely remove the necrotic tissue and secretions of wounds, stimulate granulation tissue production, reduce bacterial infection, and promote wound healing (4). Basically, NPWT is an mechanical unit with a tube connecting to a suction device which creates a sub atmospheric pressure between the wound and the outside to remove the exudate and accelerate the healing (5). Although NPWT is widely considered effective, and there are large differences in reports between clinical literature, and there is a lack of quantitative analysis of research data. In this study, the effectiveness and safety of NPWT were quantitatively investigated by means of a meta-analysis to integrate the results of multiple studies, thereby reducing bias and chance. We present the following article in accordance with the PRISMA reporting checklist (available at https://dx.doi.org/10.21037/apm-21-2476).

\section{Methods}

\section{Search strategy}

The databases of PubMed, Embase, Ovid, and the Cochrane library were selected as the search platforms for this study, and the search keywords were "vacuum-assisted closure therapy" OR "negative pressure wound therapy" OR "diabetic foot".

\section{Inclusion and exclusion criteria of literature}

The inclusion criteria were as follows: (I) the type of literature was randomized controlled trial (RCT); (II) year of publication was after 2010; (III) participants were all patients with DF; (IV) the study divided the participants into the intervention group and control group for the study. The intervention group was treated with negative pressure debridement (or mentioned as vacuum negative pressure device), while the control group was treated with conventional wound treatment; (V) the study indicators included wound healing rate, wound healing time, incidence of adverse reactions, amputation rate, mortality, recurrence rate, and other indicators.

The exclusion criteria were as follows: (I) non-RCT; (II) study with total sample size less than 10; (III) non-diabetesinduced foot trauma; (IV) studies lacking outcome measures or with incomplete data.

\section{Literature bias analysis}

According to the criteria in the Cochrane Handbook for Systematic Reviews of Interventions (6), six bias aspects were screened, including (I) the generation of random sequences, (II) classification concealment, (III) blind method, (IV) whether outcome assessment was incomplete, (V) selective reporting, (VI) other biases. The bias risk of the included studies were assessed by the judgement of "unclear", "low risk", "high risk", we consider studies with no more than two "high risks" as a study with good quality.

\section{Data collection}

Databases were searched and a list of articles was compiled by two researchers. After filtering out repeat articles, preliminary screening was performed by reading the title and abstract of the articles. Further screening was performed by reading the full text and the articles were filtered according to the inclusion and exclusion criteria. If the opinions of the two researchers were not uniform during the screening process, a third person was consulted for arbitration. Data was collected during full text reading, such as author, publication date, number of patients with intervention, gender ratio, age, body mass index (BMI), glycosylated hemoglobin level, ulcer area, ulcer location, intervention time, and follow-up time. The data was transformed for further synthesis (e.g., indicators expressed as $\%$ of all literatures were converted into the actual number of patients).

\section{Statistical methods}

The software RevMan version 5.4 (Review Manager; The Cochrane Collaboration, 2020) was used for the synthesis. (I) Continuous variables were reported using weighted mean difference (WMD) and 95\% confidence interval (CI) as statistics, and binary variables were reported using odds ratio (OR) and 95\% CI; (II) Statistics were presented in the form of forest plot; (III) Test level $\alpha=0.05$; (IV) Literature heterogeneity was analyzed using $\mathrm{I}^{2}$ analysis and 


\section{Identification of studies via databases and registers}

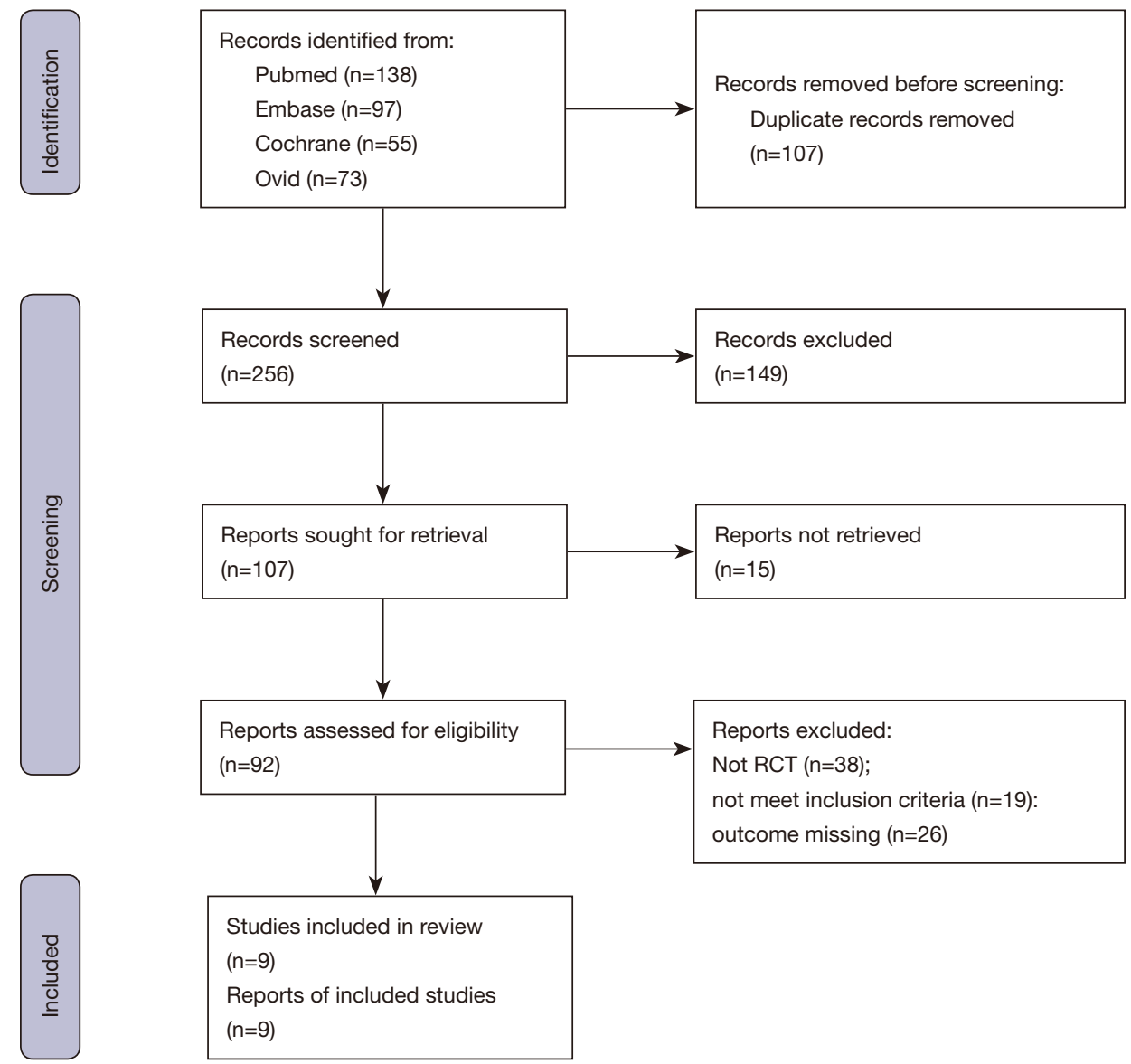

Figure 1 Flow chart of literature search and screening.

Q calibration, and heterogeneity of the results was indicated by $\mathrm{I}^{2}>25 \%$ or $\mathrm{P}<0.1 ;(\mathrm{V})$ If heterogeneity existed between studies, the random effects model analysis was used; if heterogeneity did not exist, fixed effects model analysis was used; (VI) If the existence of heterogeneity between literatures was suggested, sensitivity analysis was performed by exclusion method one by one, and a funnel plot was used to report publication bias.

\section{Results}

\section{Literature screening procedure}

In this study, 363 articles were initially screened, and after duplicate check, primary screening, and re-screening, a total of 9 articles were included, including 943 participants overall. The screening process is shown in Figure 1.

\section{Basic characteristics of literatures}

Table 1 provides a table record of the basic characteristics of the 9 RCTs included in this study. The number of participants in each study ranged from 22 to 345 . The age range of participants was 50.3-69.5 years. The intervention time ranged from 7 to 56 days. The observation date ranged from 1 to 6 months. The details are shown in Table 1 .

\section{Literature intervention operation}

Table 2 shows the number of participants with intervention, 


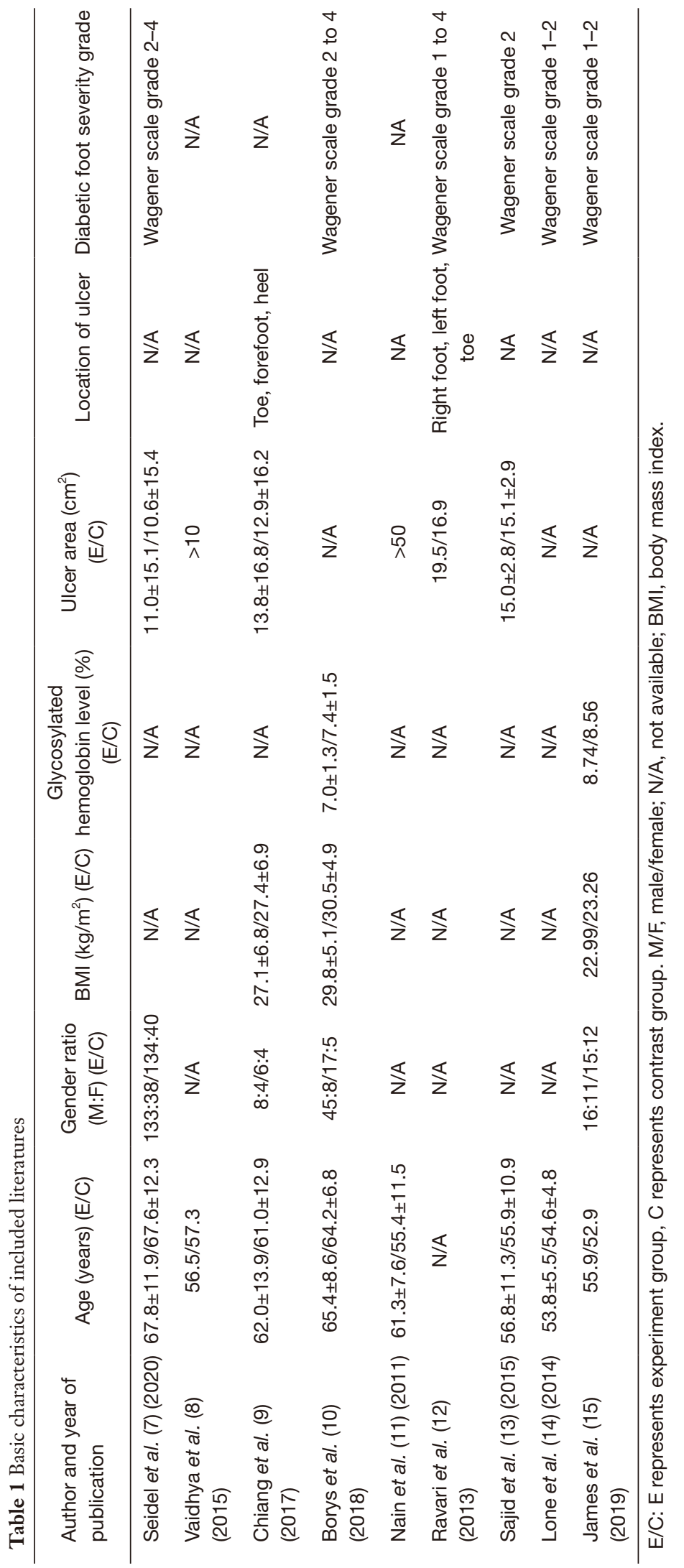


Table 2 Interventions for included studies

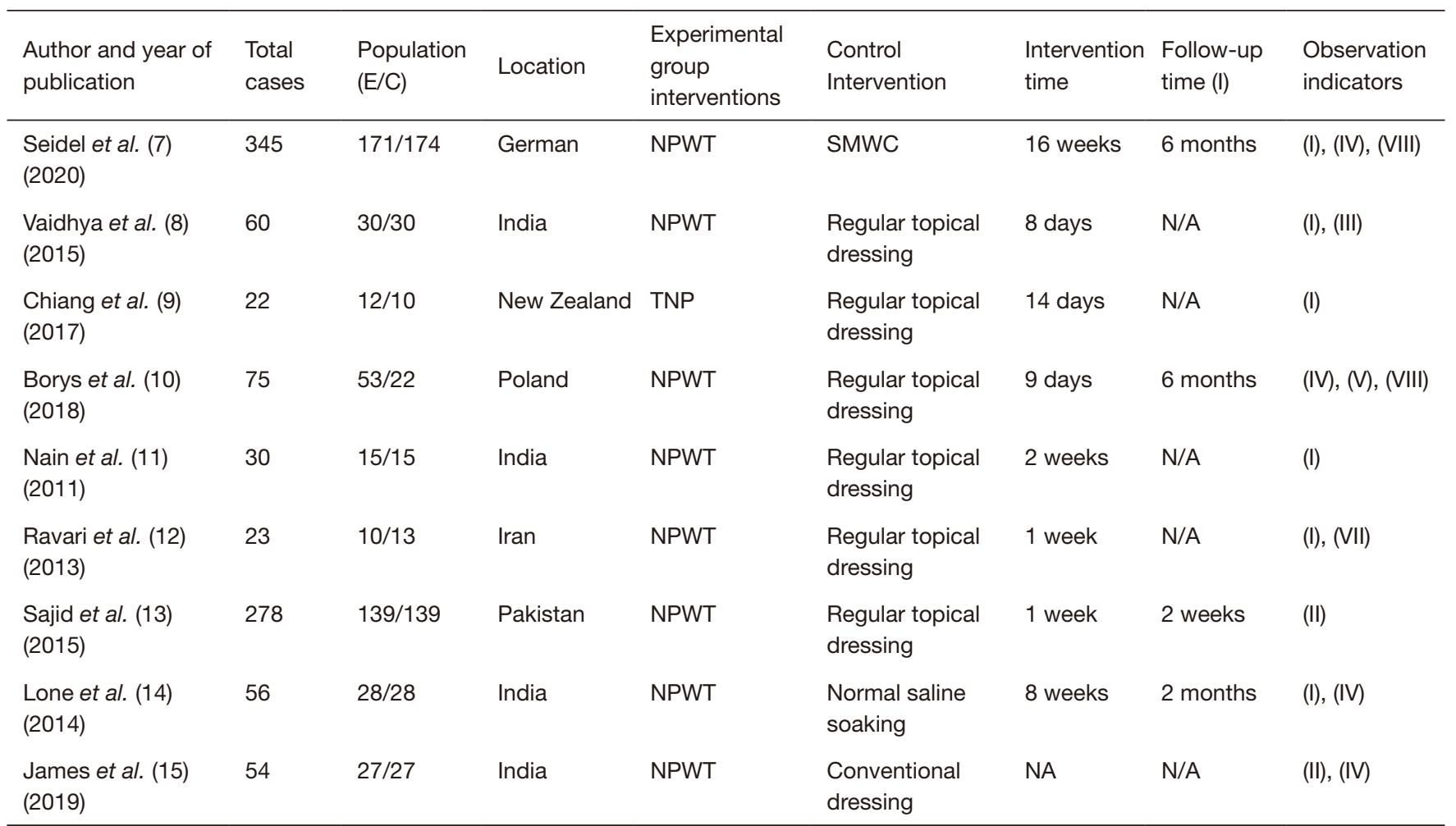

Notes: (I) the rate of ulcer formation; (II) amount of time until granulation tissue formation; (III) adverse events; (IV) amputation rate; (V) time of ulcer until was healed; (VI) SF-36; (VII) patient satisfaction; (VIII) recurrence rates. T represents intervention group, C represents control group, NA, not available; NPWT, negative pressure wound therapy, SMWC, standard moist wound care; TNP, topical negative pressure.

intervention methods, time, follow-up time, and observation indicators.

\section{Risk analysis of literature bias}

According to the Cochrane Handbook of Systems, 9 included studies were assessed for bias. The study by Nain et al. (11) [2011] did not use the concealed allocation method and only used the odd and even allocation method, so it was judged as high risk. Due to the difficulty in implementing the blind method during the intervention, only two studies mentioned the implementation of the blind method, and the remaining studies were judged as unclear risk. The study by Lone et al. (14) [2014] mentioned participants who were lost to follow-up, but did not specify the number of such patients or the reasons for loss to follow-up, so it was judged as high risk (Figures 2,3).

\section{Meta-analysis result report}

\section{Wound healing rate}

A total of 6 studies $(7-9,11,12,14)$ reported the wound healing rate indicators of participants. There was no statistical heterogeneity in the literatures $\left(\mathrm{I}^{2}=0 \%, \mathrm{P}=0.74\right)$. Combined analysis using the fixed effects model showed that the wound healing rate difference of the two groups was statistically significant ( $\mathrm{OR}=3.60,95 \% \mathrm{CI}: 2.38$ to 5.45 , $\mathrm{P}<0.001)$. The forest plot is shown in Figure 4.

\section{Granulation tissue formation time}

A total of 3 studies $(8,13,15)$ reported the indicators of granulation tissue formation in patients. There was no statistical heterogeneity in the literatures $\left(\mathrm{I}^{2}=0 \%, \mathrm{P}=0.89\right)$. Combined analysis using fixed effects model showed that the difference in granulation tissue formation time between two groups was statistically significant (MD $=-8.95,95 \%$ 


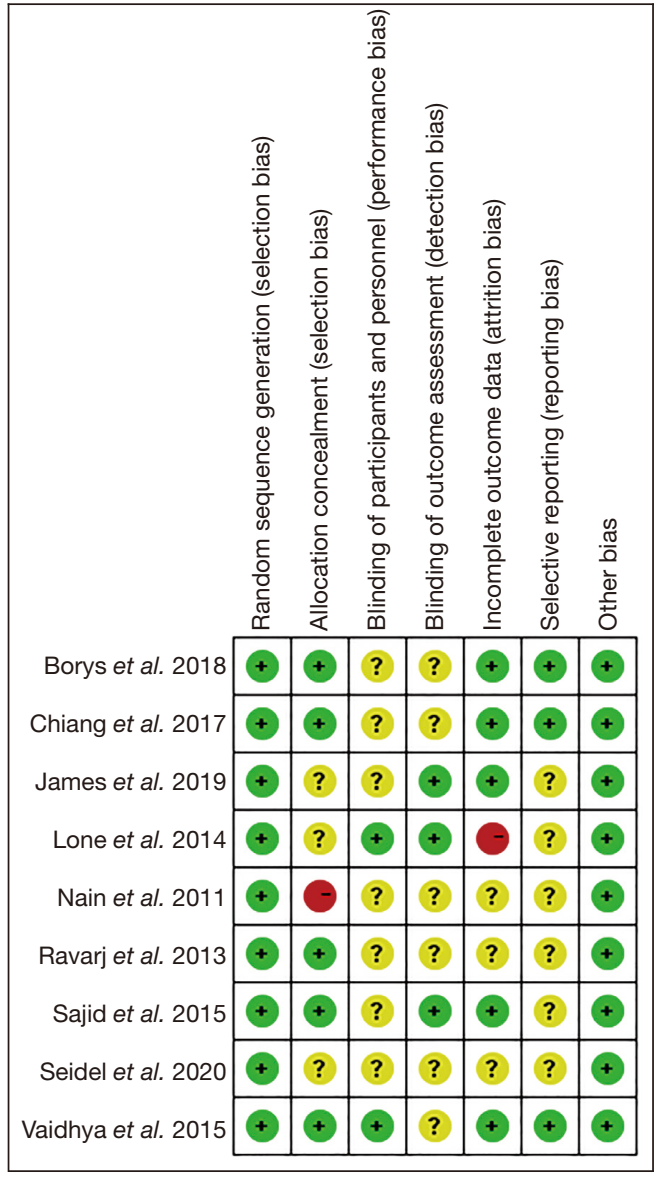

Figure 2 Literature risk assessment chart.
CI: -10.26 to $-7.64, \mathrm{P}<0.001)$. The forest plot is shown in Figure 5.

\section{Incidence of adverse events}

A total of 2 studies $(7,8)$ reported the indicators of incidence rate of adverse events in patients. The studies had no statistical heterogeneity $\left(\mathrm{I}^{2}=0 \%, \mathrm{P}=0.60\right)$. Combined analysis using fixed effects model showed that the adverse events rate difference between the two groups was not statistically significant $(\mathrm{OR}=0.49,95 \% \mathrm{CI}: 0.10$ to $2.42, \mathrm{P}=0.38)$. The forest plot is shown in Figure 6.

\section{Amputation rate}

A total of 6 studies $(7,9,10,12,14,15)$ reported the indicators of patient amputation rate. There was no statistical heterogeneity among these studies $\left(\mathrm{I}^{2}=0 \%, \mathrm{P}=0.94\right)$. Combined analysis using the fixed effects model showed that the difference in amputation rate between the two groups was not statistically significant $(\mathrm{OR}=0.33,95 \% \mathrm{CI}$ : 0.09 to $1.26, \mathrm{P}=0.10)$. The forest plot is shown in Figure 7 .

\section{Sensitivity analysis and publication bias}

Since no statistically significant heterogeneity among the literatures, there was no heterogeneity investigation performed. Sensitivity analysis was conducted by comparing the result of the fixed and the random effect mode of synthesis, which show no great gap between them. We do

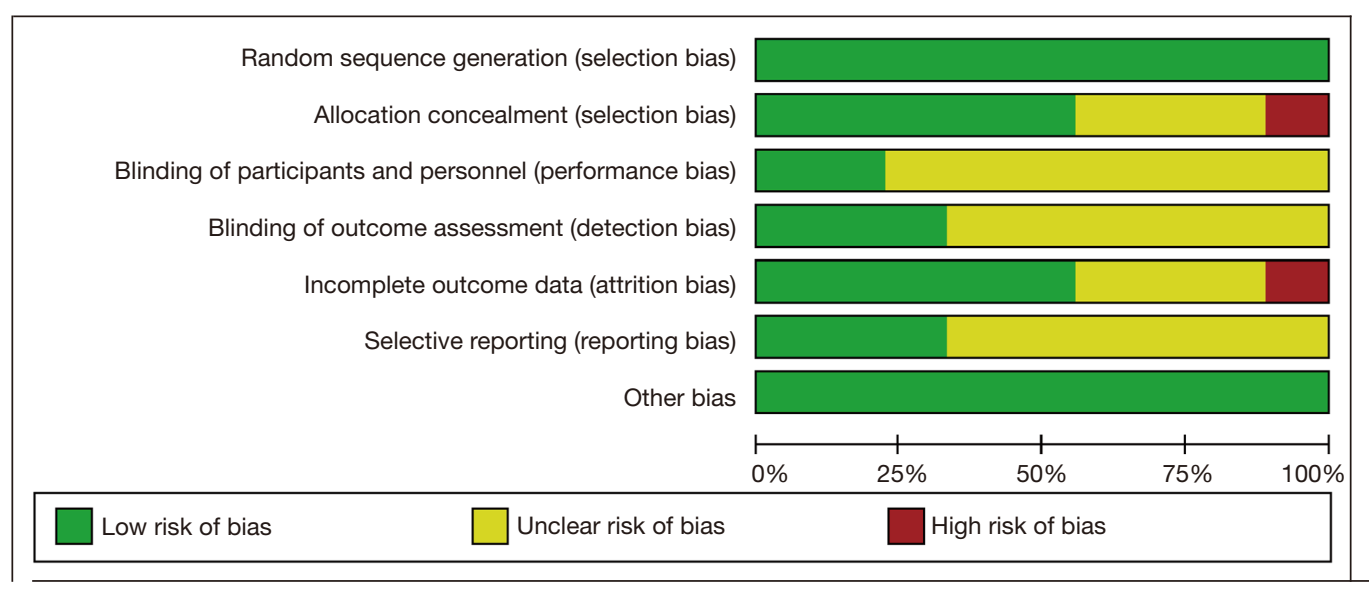

Figure 3 Overall risk of bias of studies. 


\begin{tabular}{|c|c|c|c|c|c|c|c|c|c|c|}
\hline Studv or Subgroup & $\begin{array}{l}\text { NPW } \\
\text { Events }\end{array}$ & $\begin{array}{l}\text { T } \\
\text { Total }\end{array}$ & $\begin{array}{l}\text { Standar } \\
\text { Events }\end{array}$ & $\begin{array}{l}\text { Ird } \\
\text { Total }\end{array}$ & Weight & $\begin{array}{c}\text { Odds Ratio } \\
\text { M-H, Fixed, 95\% Cl }\end{array}$ & & $\begin{array}{r}\text { Odds I } \\
\text { M-H, Fixer }\end{array}$ & $\begin{array}{l}\text { Ratio } \\
\text { d, } 95 \% \mathrm{Cl}\end{array}$ & \\
\hline Chiang et al 2017 & 8 & 12 & 5 & 10 & $7.4 \%$ & $2.00[0.36,11.23]$ & & & & \\
\hline Lone et al 2014 & 21 & 28 & 15 & 28 & $15.2 \%$ & $2.60[0.84,8.07]$ & & & & \\
\hline Nain et al 2011 & 11 & 15 & 7 & 15 & $7.6 \%$ & $3.14[0.68,14.50]$ & & & & \\
\hline Ravarj et al 2013 & 6 & 10 & 2 & 13 & $2.8 \%$ & $8.25[1.15,59.00]$ & & & & \\
\hline Seidel et al 2020 & 153 & 171 & 114 & 174 & $48.2 \%$ & $4.47[2.51,7.99]$ & & & - & \\
\hline Vaidhya et al 2015 & 20 & 30 & 14 & 30 & $18.9 \%$ & $2.29[0.80,6.50]$ & & & & \\
\hline Total $(95 \% \mathrm{Cl})$ & & 266 & & 270 & $100.0 \%$ & $3.60[2.38,5.45]$ & & & & \\
\hline Total events & 219 & & 157 & & & & & & & \\
\hline $\begin{array}{l}\text { Heterogeneity: } \mathrm{Chi}^{2}= \\
\text { Test for overall effect }\end{array}$ & $\begin{array}{l}2.74, \mathrm{df}= \\
Z=6.050\end{array}$ & $\begin{array}{l}5(\mathrm{P}= \\
P \leq 0.0\end{array}$ & $\begin{array}{l}0.74) ;\left.\right|^{2}= \\
00001)\end{array}$ & & & & 0.01 & $\begin{array}{c}0.1 \\
\text { Favours [NPWT] }\end{array}$ & $\begin{array}{cc}10 & 10 \\
\text { Favours [Standard] }\end{array}$ & 100 \\
\hline
\end{tabular}

Figure 4 Forest plot of wound healing rate indicators.

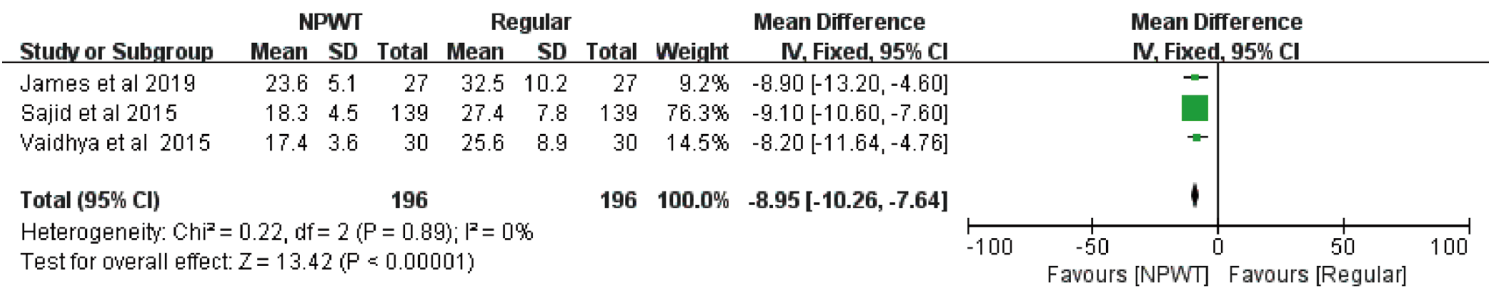

Figure 5 Forest plot of granulation tissue formation time indicators.

\begin{tabular}{|c|c|c|c|c|c|c|c|c|c|c|c|}
\hline Studv or Subgroup & $\begin{array}{l}\text { NPW } \\
\text { Events }\end{array}$ & Total & $\begin{array}{l}\text { Regulc } \\
\text { Events }\end{array}$ & $\begin{array}{l}\text { ar } \\
\text { Total }\end{array}$ & Weight & $\begin{array}{c}\text { Odds Ratio } \\
\text { M-H, Fixed, } 95 \% \text { Cl }\end{array}$ & & $\begin{array}{r}\text { Odds } \\
\text { M-H, Fixe }\end{array}$ & $\begin{array}{l}\text { Ratio } \\
\text { d, } 95 \% \mathrm{Cl}\end{array}$ & & \\
\hline Borys et al 2018 & 2 & 53 & 1 & 22 & $31.5 \%$ & $0.82[0.07,9.58]$ & & $\Rightarrow$ & & & \\
\hline Seidel et al 2020 & 1 & 171 & 3 & 174 & $68.5 \%$ & $0.34[0.03,3.26]$ & & & & & \\
\hline Total $(95 \% \mathrm{Cl})$ & & 224 & & 196 & $100.0 \%$ & $0.49[0.10,2.42]$ & & & & & \\
\hline Total events & 3 & & 4 & & & & & & & & \\
\hline \multicolumn{7}{|c|}{$\begin{array}{l}\text { Heterogeneity: } \mathrm{Chi}^{2}=0.28, \mathrm{df}=1(\mathrm{P}=0.60) ; \mathrm{I}^{2}=0 \% \\
\text { Test for overall effect: } \mathrm{Z}=0.88(\mathrm{P}=0.38)\end{array}$} & 0.01 & $\begin{array}{c}0.1 \\
\text { Favours [NPWT] }\end{array}$ & Favours [ & $\begin{array}{l}10 \\
\text { [Regular] }\end{array}$ & 100 \\
\hline
\end{tabular}

Figure 6 Forest plot of incidence of adverse events.

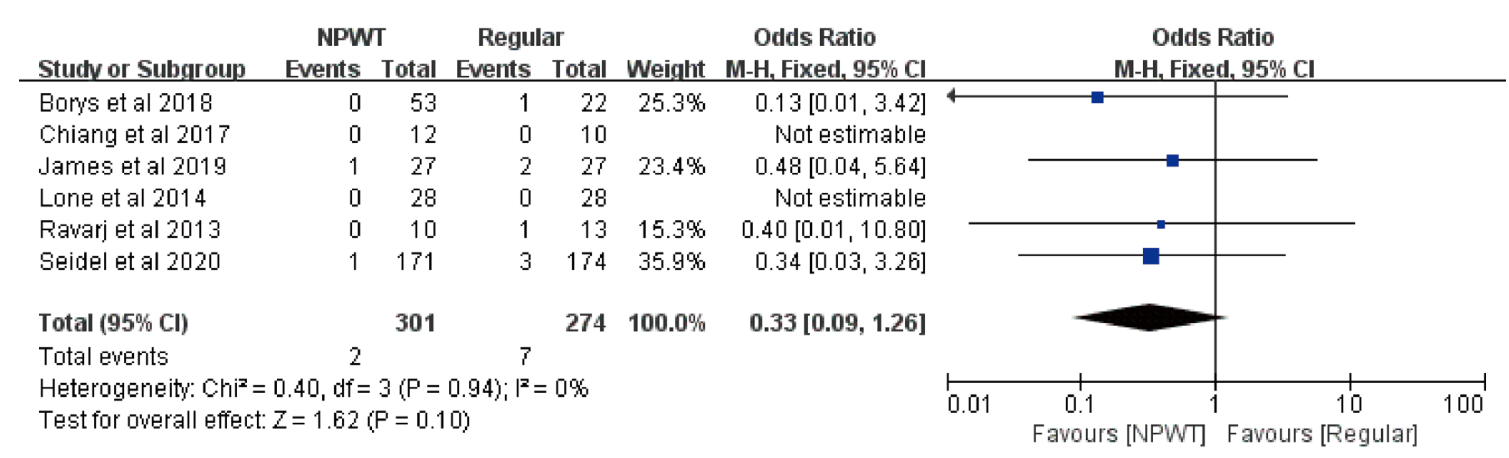

Figure 7 Forest plot for amputation rate. 


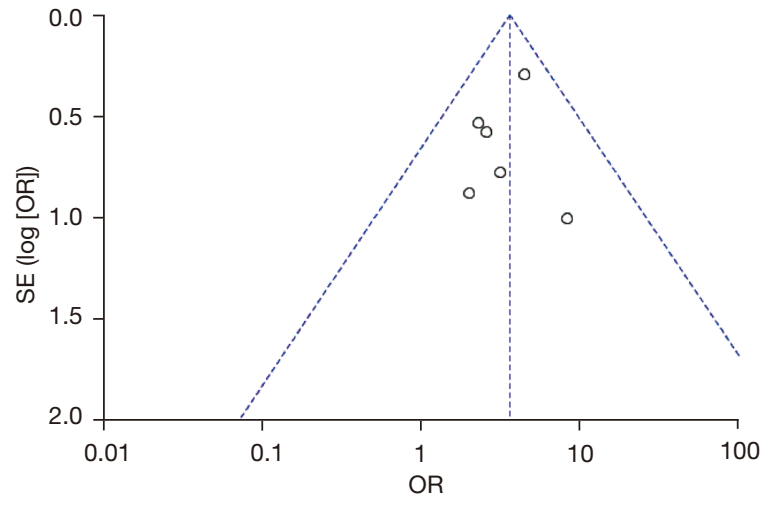

Figure 8 Funnel plot of wound healing rate.

not sense any location bias because all the literatures show no heterogeneity. Funnel plot analysis was performed for wound healing rate indicators, with uneven distribution on both sides, suggesting possible publication bias, as shown in Figure 8 .

\section{Discussion}

In diabetic patients, under the state of elevated blood glucose, the peripheral nerves and blood vessels are subjected to abnormal cell proliferation, vascular endothelial cell disorder, the micro-environment change, and inflammatory response, which are the main reasons why DF is difficult to heal (16). Negative pressure wound therapy can use different internal and external pressures to drain the deep-seated necrotic tissue and secretions of the wound, reduce wound infection, and keep the wound moist, so as to promote wound healing (17). However, the reported indicators of its effects in clinical practice are diverse, the data are different, and there is a lack of effective combining. In a meta-analysis by Liu et al. (18), 11 RCTs were identified and 1044 patients included, but 7 of the included articles were published before year 2010, and most of them did not describe the randomised methods and processed, and only 3 of them described the allocation concealment. In this study, 9 RCT articles related to NPWT therapy published in the recent 10 years were selected, involving a total of 943 participants, all of them offered the randomised methods and only one of them did not offer the allocation concealment. The four indicators of wound healing rate, granulation tissue formation time, incidence of adverse reactions, and amputation rate were statistically analyzed. The results showed that the wound healing rate was
$(\mathrm{OR}=3.60, \mathrm{P}<0.0001)$ in patients treated with NPWT comparing to those treated with conventional moist therapy, suggesting that NPWT could effectively promote wound healing. In regards to granulation formation time that of NPWT patients was significantly shorter than that of conventional therapy, the merge statistical value (MD $=-8.95, \mathrm{P}<0.001)$, suggesting that the wound healing was faster in patients with NPWT. The incidence of adverse events (infection, pain, etc.) was reported in two studies, and there was no significant difference between the two therapies $(\mathrm{P}>0.05)$. The amputation rate was reported in 6 studies, and there was no significant difference between the two groups $(\mathrm{P}>0.05)$, suggesting that NPWT therapy was safe and reliable.

Traditional wound care adopts the improvement of various dressings to promote wound healing, but the dressing may easily adhere to the wound scab, damaging the new granulation when changing, thus affecting the wound healing (19). The method of NPWT can improve the wound microenvironment, change microvascular hemodynamics, control wound infection, and promote endothelial cell regeneration (20). Wound edema, bleeding, pain, and infection were the most common adverse effects during treatment, the results of this study showed that NPWT did not increase the incidence of adverse effects, amputation rate was lower than with conventional treatment, but there was no statistical difference between the two treatments. In this study, the negative pressure value adopted in the NPWT method was not statistically analyzed. Some studies (21) showed that the negative pressure value should be maintained at $50-200 \mathrm{mmHg}$, appropriately adjusted to avoid bleeding tendency of the wound, and the wound should be fully closed. In a guideline released by Everett (22), to avoid the outcome of amputation, the history of peripheral arterial disease should be fully assessed, and the appropriate recognition of infection and treatment with antibiotics in diabetic foot infection is imperative, also the blood glucose should be optimized to improve wound healing and limit adverse effects on cellular immunity and infection, and multidisciplinary care could be helpful.

In this analysis, due to difficulty implementing the blind method, only two studies mentioned the implementation of the blind method, which may have produced the implementation bias. The funnel plot showed asymmetry between the two sides, suggesting that there may have been some publication bias. In addition, there were many outcome measures reported in the study, such as the speed 
of wound reduction, recurrence rate, treatment costs, and other indicators that were not included in the statistics, which may have caused incomplete statistics. Follow-up time was not mentioned in some studies, which may have caused follow-up bias. More samples are still needed to fully investigate the effectiveness of NPWT. In addition, recent study (23) have shown that NPWT may affect gene expression differences in diabetic patients, which may become a new research direction of NPWT.

\section{Conclusions}

In this meta-analysis on the efficacy and safety of NPWT for DF, a total of 9 articles were included with a total of 943 participants. The results showed that NPWT can effectively accelerate wound healing, which is equally safe with general routine treatment. However, the negative pressure value should be appropriately maintained and adjusted to avoid bleeding tendency of the wound.

\section{Acknowledgments}

Funding: None.

\section{Footnote}

Reporting Checklist: The authors have completed the PRISMA reporting checklist. Available at https://dx.doi. org/10.21037/apm-21-2476

Conflicts of Interest: All authors have completed the ICMJE uniform disclosure form (available at https://dx.doi. org/10.21037/apm-21-2476). The authors have no conflicts of interest to declare.

Ethical Statement: The authors are accountable for all aspects of the work in ensuring that questions related to the accuracy or integrity of any part of the work are appropriately investigated and resolved.

Open Access Statement: This is an Open Access article distributed in accordance with the Creative Commons Attribution-NonCommercial-NoDerivs 4.0 International License (CC BY-NC-ND 4.0), which permits the noncommercial replication and distribution of the article with the strict proviso that no changes or edits are made and the original work is properly cited (including links to both the formal publication through the relevant DOI and the license).
See: https://creativecommons.org/licenses/by-nc-nd/4.0/.

\section{References}

1. Chong SJ, Kwan TM, Weihao L, et al. Maintenance of negative-pressure wound therapy while undergoing hyperbaric oxygen therapy. Diving Hyperb Med 2011;41:147-50.

2. Zaitseva EL, Tokmakova AY, Shestakova MV, et al. The Study of Influence of Different Methods of Local Treatment on Wound Healing in Patients with Diabetic Foot Ulcers. Vestn Ross Akad Med Nauk 2016;71:466-71.

3. Armstrong DG, Marston WA, Reyzelman AM, et al. Comparative effectiveness of mechanically and electrically powered negative pressure wound therapy devices: a multicenter randomized controlled trial. Wound Repair Regen 2012;20:332-41.

4. Karatepe O, Eken I, Acet E, et al. Vacuum assisted closure improves the quality of life in patients with diabetic foot. Acta Chir Belg 2011;111:298-302.

5. Uğurlar M, Sönmez MM, Armağan R, et al. Comparison of two different vacuum-assisted closure (VAC) treatments of multiple chronic diabetic foot wounds in the same extremity. Foot Ankle Surg 2017;23:173-8.

6. The Cochrane Collaboration. Cochrane Handbook for Systematic Reviews of Interventions (EB/OL). Available online: http://www.cochrane.org

7. Seidel D, Storck M, Lawall H, et al. Negative pressure wound therapy compared with standard moist wound care on diabetic foot ulcers in real-life clinical practice: results of the German DiaFu-RCT. BMJ Open 2020;10:e026345.

8. Vaidhya N, Panchal A, Anchalia MM. A New Costeffective Method of NPWT in Diabetic Foot Wound. Indian J Surg 2015;77:525-9.

9. Chiang N, Rodda OA, Sleigh J, et al. Effects of topical negative pressure therapy on tissue oxygenation and wound healing in vascular foot wounds. J Vasc Surg 2017;66:564-71.

10. Borys S, Hohendorff J, Koblik T, et al. Negative-pressure wound therapy for management of chronic neuropathic noninfected diabetic foot ulcerations - short-term efficacy and long-term outcomes. Endocrine 2018;62:611-6.

11. Nain PS, Uppal SK, Garg R, et al. Role of negative pressure wound therapy in healing of diabetic foot ulcers. J Surg Tech Case Rep 2011;3:17-22.

12. Ravari H, Modaghegh MH, Kazemzadeh GH, et al. Comparision of vacuum-asisted closure and moist wound dressing in the treatment of diabetic foot ulcers. J Cutan 
Aesthet Surg 2013;6:17-20.

13. Sajid MT, Mustafa Qu, Shaheen N, et al. Comparison of Negative Pressure Wound Therapy Using VacuumAssisted Closure with Advanced Moist Wound Therapy in the Treatment of Diabetic Foot Ulcers. J Coll Physicians Surg Pak 2015;25:789-93.

14. Lone AM, Zaroo MI, Laway BA, et al. Vacuum-assisted closure versus conventional dressings in the management of diabetic foot ulcers: a prospective case-control study. Diabet Foot Ankle 2014. doi: 10.3402/dfa.v5.23345.

15. James SMD, Sureshkumar S, Elamurugan TP, et al. Comparison of Vacuum-Assisted Closure Therapy and Conventional Dressing on Wound Healing in Patients with Diabetic Foot Ulcer: A Randomized Controlled Trial. Niger J Surg 2019;25:14-20.

16. Liu Z, Dumville JC, Hinchliffe RJ, et al. Negative pressure wound therapy for treating foot wounds in people with diabetes mellitus. Cochrane Database Syst Rev 2018;10:CD010318.

17. Shu X, Shu S, Tang S, et al. Efficiency of stem cell based therapy in the treatment of diabetic foot ulcer: a metaanalysis. Endocr J 2018;65:403-13.

18. Liu S, He CZ, Cai YT, et al. Evaluation of negativepressure wound therapy for patients with diabetic foot

Cite this article as: Chen L, Zhang S, Da J, Wu W, Ma F, Tang C, Li G, Zhong D, Liao B. A systematic review and meta-analysis of efficacy and safety of negative pressure wound therapy in the treatment of diabetic foot ulcer. Ann Palliat Med 2021;10(10):10830-10839. doi: 10.21037/apm-21-2476 ulcers: systematic review and meta-analysis. Ther Clin Risk Manag 2017;13:533-44.

19. Dumville JC, Hinchliffe RJ, Cullum N, et al. Negative pressure wound therapy for treating foot wounds in people with diabetes mellitus. Cochrane Database Syst Rev 2013;(10):CD010318.

20. Huang C, Leavitt T, Bayer LR, et al. Effect of negative pressure wound therapy on wound healing. Curr Probl Surg 2014;51:301-31.

21. Lerman B, Oldenbrook L, Ryu J, et al. The SNaP Wound Care System: a case series using a novel ultraportable negative pressure wound therapy device for the treatment of diabetic lower extremity wounds. J Diabetes Sci Technol 2010;4:825-30.

22. Everett E, Mathioudakis N. Update on management of diabetic foot ulcers. Ann N Y Acad Sci 2018;1411:153-65.

23. Frykberg RG, Franks PJ, Edmonds M, et al. A Multinational, Multicenter, Randomized, Double-Blinded, Placebo-Controlled Trial to Evaluate the Efficacy of Cyclical Topical Wound Oxygen (TWO2) Therapy in the Treatment of Chronic Diabetic Foot Ulcers: The TWO2 Study. Diabetes Care 2020;43:616-24.

(English Language Editor: J. Jones) 